\title{
Sobre os aspectos clínicos e a complexidade do trabalho: as clínicas do trabalho compreendidas pela perspectiva da Psicossociologia
}

\author{
Marcos Mariani Casadore \\ Universidade Estadual Paulista, Faculdade de Ciências e Letras de Assis (Assis, SP, Brasil) e \\ Faculdades Integradas de Ourinhos (Ourinhos, SP, Brasil)
}

O surgimento das denominadas "Clínicas do Trabalho" como um agrupamento de campos metodológicos evidenciados por uma perspectiva clínica de análise da complexidade das relações de trabalho e de compreensão da interação entre questões subjetivas e organizacionais do trabalho - aponta também para a leitura "ampliada" e multifacetada inerente à psicologia do trabalho atual. Embora não constituam uma escola única de pensamento, as Clínicas do Trabalho compartilham posicionamentos críticos frente às problemáticas que envolvem a intricada relação entre subjetividade e trabalho, tendo como principais interesses suas dimensões simbólicas e culturais, inerentes às vinculações interpessoais, e a questão da atividade no trabalho (i.e., ação e poder de ação do sujeito na situação de trabalho). A pesquisa, que atrela os recortes social e clínico, extrapola a definição mais técnica ou formal de trabalho, emprestando a ela a ideia de implicação subjetiva bem como de construção de significados e sentidos protagonizados pelo sujeito em situação, considerado essencialmente em sua dimensão histórica e como ator social; suas propostas de intervenção vêm conjuntamente, nesta mesma perspectiva, e buscam a construção de um saber inerente à realidade do trabalho, inseparável da experiência de onde emerge e dos sujeitos que a constroem pautando tal compreensão justamente pela complexidade da situação, junto de seus conflitos, dificuldades e questionamentos. Neste artigo, buscamos discutir algumas características fundamentais desta perspectiva metodológica voltada às questões do trabalho a partir das contribuições da Psicossociologia francesa.

Palavras-chave: Clínicas do trabalho, Psicologia do trabalho, Perspectiva clínica, Psicossociologia, Psicodinâmica do trabalho, Clínica da atividade.

On the clinical aspects and the complexity of the work: the clinics of work understood by psychosociologycal perspective

The appearing of so-called "Clinics of Work" as a grouping of methodological fields - evidenced by a clinical perspective to analyze the complexity of labor relations and understanding the interaction between subjective and organizational labor issues - also points to this "enlarged" and multifaceted understanding inherent in the actual Work psychology. Although they do not constitute a single school of thought, those Clinics of Work share critical positions regarding the problems that involve the intricate relationship between subjectivity and work, having as main interests their symbolic and cultural dimensions, inherent in interpersonal connections, and the question of the activity in the work (ie, action and power of action of the subject in the work situation). The research, which links the social and clinical aspects, goes beyond the more technical or formal definition of work, lending it the idea of subjective implication, as well as the construction of meanings carried out by the subject in situation, considered essentially in its historical dimension and as a social actor; their proposals for intervention come together in this same perspective and seek to construct a knowledge inherent in the reality of work, inseparable from the experience from which it emerges and from the subjects who construct it - setting out its understanding precisely in the complexity of the situation, with its conflicts, difficulties and questions. In this article, we intend to discuss some fundamental characteristics of this methodological perspective focused on the issues of work, from the contributions of the french Psychosociology.

Keywords: Clinics of Work, Work psychology, Clinical aspects, Psychosociology, Psychodynamics of work, Activity clinic. 


\section{Introdução}

$\mathrm{O}$ surgimento de uma perspectiva clínica ampliada da compreensão do trabalho aponta também para a complexidade inerente àquilo que entendemos como fatores e variáveis próprios dos estudos de uma psicologia do trabalho na atualidade. As pesquisas estendem-se não só metodologicamente, buscando diálogos interdisciplinares dentro das ciências sociais e fazendo uso de uma multiplicidade de leituras aplicadas e dos instrumentos de pesquisa, mas, ainda, ampliam-se os objetos de interesse privilegiados por diagnósticos e intervenções organizacionais considerando, principalmente, a análise do sujeito e sua relação estabelecida com a atividade do trabalho.

A organização do trabalho responde diretamente às questões culturais e sociais e, consequentemente, ao longo dos tempos, passa por transformações significativas, estruturais. Singer (2000) realiza uma leitura crítica dessas mudanças, numa perspectiva panorâmica, ao destacar os principais deslocamentos setoriais do trabalho ao longo da modernidade, acompanhando, ainda, mudanças em padrão de consumo e, consequentemente, todo um reordenamento social no que concerne a trabalho e emprego. Num cenário mais atual, como salientam, por exemplo, Goulart e Guimarães (2002), a reestruturação do trabalho acompanha certas lógicas atreladas à globalização, vigente com mais força desde a década de 1990: o modelo político-econômico neoliberal, que ganha espaço significativo na dinâmica das relações geopolíticas globais, acarreta mudanças econômicas e culturais em conjuntura social e, mais especificamente, no mundo do trabalho. Ainda segundo as autoras, poderíamos destacar, numa perspectiva abrangente, entre as mudanças consequenciais, o advento de privilégios concebidos a grandes empresas e não mais necessariamente aos Estados, bem como centros de decisão, poder e controle constituídos, principalmente, pelos maiores conglomerados econômicos.

Tal reorganização também implicaria uma ressignificação constante acerca do sentido do trabalho. Sem necessariamente nos voltarmos às questões que se referem à identidade do trabalhador, perpassadas pelos registros imaginários e simbólicos e estabelecidas numa perspectiva subjetiva, podemos nos aproximar de leituras macropolíticas sobre as consequências de tais transformações naquilo que compreenderíamos sobre a atividade do trabalho. Num estudo de caráter sociológico publicado previamente (Casadore, 2010), por exemplo, destacamos as transformações no mundo do trabalho vinculadas intimamente a um reordenamento de valores e prioridades culturais em nossa sociedade atual: se na sociedade industrial poderíamos pensar proeminentemente na questão da produção, atualmente nossa sociedade parece privilegiar o consumo. $\mathrm{O}$ trabalho, atravessado por essas questões, perderia espaço como sendo essencialmente um produtor de sentido e se atrelaria mais à imagem ou status consequente de sua estruturação, ganhando valorização, principalmente, como aquele que oferece suporte e condição para o consumo.

Mas, ao retomarmos o debate sobre sua organização e articulação, percebemos que o mundo do trabalho, respondendo, assim, não só às transformações geopolíticas e econômicas, mas, ainda, às evoluções tecnológicas e produtivas, estabelece novas dinâmicas relacionais. Os modos de gestão, por exemplo, modificam-se e atendem às exigências contextuais - como salienta Chanlat (1995). Na perspectiva do autor, as mudanças de gestão também devem considerar o desenvolvimento dos estudos sobre o trabalho e uma compreensão aprimorada acerca do sujeito trabalhador e seu envolvimento com a atividade do trabalho. Os modelos, porém, de maneira geral, começam a se pautar pela flexibilidade e adaptabilidade e estabelecem, com base na excelência, uma busca implacável pela otimização da produção. Esse tipo de organização do trabalho ocasionaria, por fim, uma pressão e exigência constantes voltadas às capacidades produtivas do trabalhador, o que acarretaria outros modos de sofrimento e adoecimento vinculados à incapacidade de responder sempre e prontamente a quaisquer exigências que lhe são frequentemente impostas. 
Problemas estruturais relacionados à precarização do trabalho, tanto no que concerne à flexibilização de tarefas (aqui, podemos empregar o termo de flexploração, proposto por Bourdieu (1998)) quanto à informalidade do vínculo de trabalho - e, portanto, às incertezas ou, mesmo, aos subempregos - surgem como sendo cada vez mais comuns em nossa sociedade atual.

Nesta breve discussão, temos como objetivo estabelecer alguns pontos referentes à perspectiva clínica atrelada ao campo do trabalho - proposta como modo de inserção e posicionamento, além de suas bases metodológicas e de compreensão teórica -, tendo, como principal referencial entre suas frentes, o apoio das discussões psicossociológicas. Dessa articulação salienta-se a importância em debatermos temas atuais na conjuntura das relações de trabalho contemporâneas a partir da tal leitura crítica como possibilidade de abordagem e constituição de orientações práticas - dadas as condições dos sentidos e da organização do trabalho na atualidade, é possível construir um prolífico campo de discussão a partir das abordagens clínicas do trabalho.

\section{As clínicas do trabalho}

O aparecimento da noção de "clínicas do trabalho" é bastante recente, embora as disciplinas e fundamentações teóricas que a comporiam não o sejam. Como salienta Clot (2011b), compreenderíamos as propostas das clínicas do trabalho como próximas, compartilhando de uma mesma postura crítica, mas não passíveis de serem classificadas como uma escola ou mesmo um programa teórico: antes de qualquer coisa, pensaríamos nestas como “...uma comunidade de pesquisa em plena construção..." (p. xi), que não se restringiria a, simplesmente, delinear um panorama de compreensão do trabalho no mundo, mas, principalmente, dividiriam uma espécie de função social, intrínseca à pesquisa, voltada à transformação dos contingentes referentes ao trabalho na nossa sociedade atual. Seria, essencialmente, uma atividade coletiva que propiciaria, ainda, o desenvolvimento e a construção contínua de saberes e de conhecimento sobre nosso campo. O título desse trabalho do autor - O início de uma história? - também nos ajuda nessa tentativa inicial de elucidação das propostas das clínicas do trabalho: segundo Clot, nesta perspectiva do desenvolvimento dos saberes e práticas relacionados à compreensão complexa do trabalho, teríamos toda uma história a ser traçada e escrita, considerando, ainda, que “...aquilo que nós já compartilhamos é menos interessante do que aquilo que nós ainda não compartilhamos" (2011b, p. xiii). A prioridade aqui, voltada à potencialidade do desenvolvimento teórico e prático por vir e não aos saberes já estruturados, também carregaria certo ideário comum às concepções clínicas, que visam a transformações e reconhecem singularidades inerentes aos seus objetos de interesse científico, questões que delinearão o seguimento desta discussão.

Vale salientar, ainda, que existem obstáculos e dificuldades no estabelecimento de diálogos entre as diferentes frentes do que denominaríamos comumente de "clínicas do trabalho": como afirmam Bendassolli e Soboll (2001), embora compartilhem objetivos e finalidades convergentes, posicionamentos e até mesmo pressupostos gerais comuns, não seria possível dizer que as abordagens inseridas nesse campo sejam homogêneas. Há algumas diferenças estruturais no que concerne às fundamentações teóricas e às questões epistemológico-metodológicas que dificultariam aproximações conceituais; portanto, há uma exigência implícita ao pesquisador e à construção de sua análise para que sejam feitas as ressalvas necessárias quando da tentativa de se estabelecer articulações interdisciplinares - é imprescindível certo cuidado, principalmente no que concerne a conceituações mais específicas, para manter coerência e linearidade com relação às propostas apresentadas para compreensão e intervenção em determinado contexto.

Ao tomarmos as quatro principais clínicas do trabalho comumente apresentadas, seguindo a linha de estruturação e divisão proposta por Bendassolli e Soboll (2011) - a saber, a 
psicodinâmica do trabalho, a ergologia, a clínica da atividade e a psicossociologia -, torna-se mais evidente, quando consideradas como disciplinas independentes e junto de suas evoluções e desenvolvimentos delineados de modo muito particular, o quanto há diferenças bastante marcadas com relação às concepções teóricas que fundamentariam sua construção científica. Não temos como escopo do presente trabalho apresentar de modo mais detido e minucioso quais seriam as diferenças mais acentuadas inerentes à construção de cada um dos campos das clínicas do trabalho - apesar de reconhecermos a importância e necessidade desta discussão, teríamos aqui como prioridade neste estudo trazer à tona um debate acerca daquilo que as atravessa, de modo comum, bem como suas finalidades e posicionamentos compartilhados, ao considerá-las todas sob a égide de uma perspectiva clínica. Utilizaremos, para esse fim, discussões que se situam principalmente no campo da psicossociologia francesa e, na procura por definições de algumas noções centrais à presente explanação, delinearemos o que se entende pela ideia de clínica quando inserida neste contexto. É, portanto, a "essência" de um trabalho de cunho clínico que atravesse essas disciplinas, e o que dessas questões aproximariam abordagens tão heterogêneas, que serão os principais aspectos a serem destacados para entendermos tais perspectivas de compreensão da complexidade do trabalho.

Um dos aspectos comuns que se evidencia, apesar da diversidade teórico-metodológica que perpassaria os constructos de cada uma das clínicas do trabalho quando confrontadas umas às outras, é justamente a natureza transdisciplinar inerente ao modo como elas se estruturam como disciplinas. Mesmo que distintas, e com questões e prioridades mais particulares quando da conceituação de seus objetos de estudo, as clínicas do trabalho se caracterizam por uma leitura intricada de homem e de sociedade, de trabalho e de situação de trabalho, e justamente por isso instaura-se um constante debate que envolveria diversos campos das ciências humanas e sociais como complementares e necessários a esse tipo de abordagem complexa.

Justamente por considerarem como indissociável a relação estabelecida entre sujeito e cultura, ou seja, a consideração do homem essencialmente como ser social e simbólico, bem como por realizarem uma leitura de fenômenos sociais originados e perpassados por componentes não só objetivos, mas afetivos e imaginários, as clínicas do trabalho são obrigadas a expandir suas áreas de interesse para além de um recorte clínico mais individual e próprio da psicologia, numa tentativa de estabelecer, com constância, uma discussão teórica abrangente que se situaria em intersecções teóricas nesses diversos campos das ciências sociais.

Mesmo dentro do que conceberíamos estritamente como uma psicologia clínica já poderíamos perceber uma diversificação significativa de objetos de seu interesse: para além da individualidade, as relações interpessoais, os grupos e as instituições também aparecem como áreas potenciais de interesse de estudo. Desde as origens dessa compreensão da psicologia enquanto clínica já seria possível afirmar que seu estudo, em maior ou menor grau, considera o sujeito e seus processos psíquicos sempre como inseridos numa determinada situação Enriquez (2005), por exemplo, salienta tal intertextualidade ao pensar as relações entre a psicanálise e as ciências sociais presentes desde os textos freudianos. Essa imbricação sujeito/social acaba por ser ainda mais ampliada como objeto de estudo e, consequentemente, compreendemos as ciências clínicas também como metodologia de estudo das estruturações e dos fenômenos sociais. Para a psicologia do trabalho, essas considerações compõem a infraestrutura necessária para o surgimento das disciplinas das clínicas do trabalho e possibilitam o estabelecimento dessa perspectiva clínica comum, mesmo diante da heterogeneidade de composições e prioridades teóricas inerentes aos seus desenvolvimentos ${ }^{1}$.

É possível também situar como condição para a viabilidade e ocorrência das clínicas do trabalho uma requisição, nos planos teórico e prático, de propostas que atendessem a demandas generalizadas referentes ao sofrimento no trabalho, inseridas no campo de interesse da saúde do trabalhador, e o considerasse como fator complexo e pluridimensional, para além de uma 
leitura macro, objetivista ou particular como problemática estritamente individual. A consideração destas questões que contemplasse, ao mesmo tempo, uma perspectiva social enquanto inscritas e produzidas a partir dos modos de organização e divisão do trabalho atravessados pela cultura e contexto social - e também a subjetiva - os processos psíquicos que "respondem" a essas questões, bloqueios/impedimentos da ação do sujeito ou sua produção de sentido, bem como resistências ou mecanismos defensivos - apareceriam como posicionamento essencial das moções clínicas voltadas ao social e, mais especificamente, ao trabalho.

\section{Leitura psicossociológica acerca dos aspectos clínicos referentes ao trabalho}

Lhuilier (2011), numa leitura panorâmica acerca da constituição do que entenderíamos como clínicas do trabalho, aponta para duas correntes teóricas fundamentais em sua origem, que marcariam tanto sua abordagem metodológica quanto os recortes objetais priorizados como sendo de maior interesse: de um lado, a psicologia social clínica, e, de outro, a psicopatologia do trabalho. É a partir dessas frentes que haveria os desdobramentos subsequentes, que poderíamos agrupar, também, em dois outros caminhos, a saber, um concernente à psicodinâmica do trabalho e à psicossociologia, e outro compreendendo a clínica da atividade e a ergologia.

É a multiplicidade teórica de posicionamentos e possibilidades de leitura acerca do homem e sua relação com aspectos sociais que legitima não só a riqueza concernente aos estudos complexos que considerariam esses constructos mutuamente influentes, mas, ainda, o surgimento de correntes disciplinares embasadas em diferentes vertentes das ciências humanas e sociais: distintas com relação à infraestrutura teórico-conceitual que sustenta sua leitura científica de objeto, especificamente, mas comuns a respeito de uma postura engajada, críticoreflexiva, dos objetivos propostos relacionados a uma espécie de conscientização e emancipação e, ainda, da compreensão ampliada de homem e trabalho.

Ao nos voltarmos, enfim, aos pontos comuns às clínicas do trabalho, encontramos como nodal a questão dos estudos e intervenções que visem ao indivíduo em situação - premissa evidenciada no campo da psicossociologia por Gaulejac (2001), por exemplo. Esse aspecto, também bastante característico, de maneira geral, da própria psicologia clínica por si só, é o que confere acordo entre as veredas que se delineiam como possibilidades de inserção do pesquisador neste campo de interesse vinculado aos fatores que se relacionam ao trabalho. Como salienta Lhuilier (2011), há todo um histórico que diz respeito ao nascimento de uma perspectiva clínica, primeiramente próxima aos modelos médicos e, depois, num recorte mais próximo, possível de ser caracterizada como psicologia clínica - esta, bastante influenciada pela psicanálise freudiana enquanto modelo de clínica pelo seu método, procedimentos e produção teórica.

A psicologia clínica, porém, não se limitaria a uma compreensão acerca das enfermidades e da psicopatologia, nem se consolidaria como campo de tratamentos individuais ou, mesmo, área exclusiva do domínio teórico psicanalítico. Como destaca a autora (Lhuilier, 2011):

...os fenômenos inconscientes não bastam para explicar 'a pessoa inteira em situação', e a psicologia clínica é necessariamente levada à interdisciplinaridade (...) Os trabalhos em clínica do trabalho não podem prender-se às dimensões inconscientes, às suas dependências sexuais e infantis. Eles devem se dedicar a explicar a dinâmica social consubstancial às atividades produtivas. Dinâmica social que está ligada também à realidade das situações de trabalho, às representações de que ela é objeto (pp. 25-26).

Temos, portanto, uma proposta ampliada de clínica que se atenta não só às questões estritamente pessoais ou subjetivas, mas, ainda, às extensões desses atributos, inclusive no que 
concerniria a uma leitura do social a partir de aspectos afetivos, inconscientes, simbólicos e imaginários, próprios, originalmente, das condutas individuais. É por conta dessa proposta que as clínicas do trabalho, vinculadas ao que poderíamos definir como uma psicologia social clínica, se interessaria mais pelas interações nas quais o sujeito se inscreve e para as quais contribuiria (Lhuilier, 2011). Prezaria, inclusive, pelas dinâmicas sociais, coletivas, instauradas como consequentes dessas relações interpessoais - atravessadas, portanto, pelo registro pulsional e afetivo, sempre em movimento: aqui, também não se vincularia simplesmente a análises de cunho mais sociológico e caracterizadas por uma compreensão objetiva daquilo que se instaura culturalmente. Ao não cair, propriamente, em leituras simplesmente psicológicas ou sociológicas, mas priorizar o entremeio estabelecido numa intersecção desses dois campos maiores do saber, as clínicas do trabalho se desenvolvem sempre em perspectiva ampliada.

As investigações clínicas, portanto, expandem o alcance de seu campo de visão e interesse, mas sem desconsiderar, ainda, toda a complexidade inerente à compreensão de sujeito. Num paralelo com a prática analítica, por exemplo, Lévy (2001) salienta a ideia de que o pensamento se volta a um sujeito que assume uma posição de palavra, sempre buscando o estabelecimento de sentido às ações vivenciadas e, portanto, à sua própria história. A pesquisa e a intervenção calcadas na clínica, por fim, também têm a proposta de retomada das atribuições simbólicas do trabalho e a questão da atribuição de sentido pelo sujeito, já que, como destaca Enriquez (2006), “...os seres humanos são seres em busca de sentido. É a definição fundamental de ser humano e ser social. De outro modo, seríamos apenas animais totalmente programados" (p. 11).

Ainda na intenção de salientar pontos comuns às diferentes abordagens clínicas do trabalho, poderíamos dizer que, de modo geral, outro aspecto que atravessaria todas essas diferentes propostas seria a de pesquisa e intervenção, inseridas num contexto institucional, como práticas simultâneas. Implícito nesse posicionamento, encontraríamos a consideração essencial do ponto de vista clínico que exaltaria a particularidade de cada caso, cada encontro e cada agrupamento, bem como a ideia de uma intervenção que responderia a questões contextuais e particulares: em outras palavras, há um posicionamento responsável e ético por parte do analista-interventor, há linhas referenciais de fundamentação teórica sobre as quais se debruça para pensar o espaço e as relações, e há também instrumentos e métodos passíveis de serem aplicados na proposta de trabalho - porém, acima de tudo, é necessário considerar o que aparece como singular e o que se destaca como situacional e conjuntural, para que seja possível estabelecer um diagnóstico específico e pensar nas melhores e mais coerentes formas de ação diante de uma demanda.

Lévy (2001) nos diz, portanto, que a démarche da clínica social seria, por fim, justamente a concomitância das ações de pesquisa/diagnóstico e intervenção, atreladas ao reconhecimento - em toda a sua complexidade - dos fenômenos organizacionais e sua realidade pluridimensional; por isso, nessa perspectiva, a clínica seria, ao mesmo tempo, um modo de análise e um modo de intervenção. O que mais interessaria às abordagens clínicas do social e do trabalho, por fim, não se reduziria às questões do indivíduo, mas é, antes, uma perspectiva ampliada às interações sociais nas quais os trabalhadores se inscrevem e, ao mesmo tempo, para as quais contribuiria: seria, ainda segundo o autor, a abordagem do outro quando nas relações sociais. A leitura desse social também extrapolaria as considerações mais objetivas de pensá-lo como um acúmulo conjuntural de determinações e o trataria como sendo construído em dinâmicas coletivas e, por natureza, em constante evolução.

É neste sentido que Lhuilier (2014) apontaria para outros aspectos que despontariam como diferenciais, intrínsecos a essas questões supracitadas: além do trabalho, que visa, ao mesmo tempo, à autonomia do sujeito (e consequentemente um aumento sobre seu poder de ação) e à construção do saber e das elaborações vigentes também num movimento coletivo desses trabalhadores (relacionados diretamente com o conhecimento efetivo da prática), as clínicas do trabalho estabeleceriam outra relação na compreensão da implicação do 
pesquisador/interventor. É uma atenção diferenciada, que o coloca como fator intrínseco ao próprio processo e como sujeito que participa direta e ativamente, ao estabelecer uma relação com o espaço e com os trabalhadores muito além da neutralidade ou formalidade, toda perpassada pelos aspectos afetivos e emocionais, de ordem consciente ou inconsciente. Enriquez (1997) nos diz que o interventor trabalharia em interioridade, por se envolver diretamente na situação, e faz com que sua presença por si só seja o suficiente para suscitar certos problemas ou conflitos, já que também assume um lugar "depositário" de identificações e projeções.

Ao deslocarmos o foco da compreensão de aspectos e instâncias maiores para um nível mais específico e contextual é que passamos a considerar aquilo que se caracteriza como produção (/reprodução) de atividade e de sentido particulares a uma instituição e àqueles envolvidos diretamente. Como destaca Lhuilier (2011), é uma dinâmica social consubstancial a essa atividade produzida que seria objeto de estudo - sendo a dinâmica, ainda, ligada "...à realidade das situações de trabalho, à representações de que ela é objeto. Realidade encontrada mas também produzida por estas relações e pela práxis que elas permitem” (p. 26).

Assim, a investigação clínica se volta às relações e, ao pensar no sujeito implicado e sua compreensão e reação às situações, compreende também que estas respostas individuais dizem respeito às configurações coletivas, culturais, grupais em que se insere, bem como suas construções simbólicas e imaginárias compartilhadas.

Também no que se refere ao sujeito inserido na relação - e não só à proposta metodológica das clínicas do trabalho - vemos a conversão necessária entre compreensão/produção de sentido e ação, propriamente dita. Outro ponto de convergência destas diferentes abordagens clínicas do trabalho é seu interesse pela ação no trabalho (que ganha destaque mais explícito nas propostas da Clínica da Atividade de Yves Clot, mas atravessa essencialmente as propostas intervencionistas). Clot (2011a) o coloca como poder de agir, num sentido de poder sobre si mesmo, sobre a atividade e, ainda, sobre as resistências do real do trabalho. É necessário que pensemos, sempre, o potencial de transformação da realidade inerente às relações e dinâmicas sociais, portanto. Isso faz com que a inscrevamos numa práxis possível a partir das demandas de transformação desta realidade. Tal condição aparece imbricada à viabilização crescente de verdadeira compreensão da situação de trabalho.

A convergência das linhas teóricas das clínicas do trabalho também aparece ao estabelecerem uma leitura abrangente de sujeito, que destaca sua inserção numa cultura e o compreende sempre na relação com o outro. O sujeito, portanto, é atravessado por variáveis e forças sócio-históricas, bem como discursos e instituições contextuais - além das considerações voltadas aos seus conflitos intrapsíquicos e aspectos inconscientes. Sobressai, intrínseco a essas considerações, uma crítica contundente às abordagens de indivíduo que se calcam em perspectivas cognitivistas ou comportamentais, tidas como reducionistas ou simplistas.

O sujeito, então, como sendo muito mais do que simplesmente uma espécie de instrumento de processamentos de informações do ambiente ou visto somente como respostas comportamentais, é apreendido pelas disciplinas da clínica do trabalho principalmente em suas disposições enquanto ator social e agente produtor de sentido: é essa circunstância, por excelência, que possibilita suas propostas de diagnóstico e intervenção, colocando o trabalhador em evidência, como protagonista atuante e responsável pela construção e desenvolvimento de sua própria história e da história da organização - como corrobora, por exemplo, Enriquez (1994).

É, portanto, pela condição de construção de sentidos por parte dos trabalhadores envolvidos diretamente com a situação de trabalho que se verifica a efetivação das mudanças oriundas da intervenção. Poderíamos considerar que toda prática clínica, seja em qual contexto se situar, perpassaria pela questão do discurso e da edificação do sentido. Como coloca Lévy (2001), quando considerada a clínica social, a intervenção envolveria uma espécie de ato 
contínuo de descobertas ao mesmo tempo progressivas e ininterruptas de significações, desenvolvendo, por fim, essa emergência dos sentidos.

O pesquisador/interventor, nesse quesito, ao participar como um agente de trabalho, facilita e toma parte da construção do sentido empreendida pelos sujeitos, mas de maneira indireta e não como aquele que detém alguma resposta acerca desse sentido: mais do que ser simplesmente quem se utiliza de métodos e técnicas, é necessário que o interventor se reconheça também como sujeito implicado, que assume um papel e posicionamento em relação ao outro (relação interpessoal), mas também com relação ao próprio saber e, ainda, à elaboração de saber. Depara-se com paradoxos e questionamentos complexos, dificuldades tanto suas quanto referentes à intervenção, mas assume uma conduta modesta e "responsável" ao reconhecer tais problemáticas todo o tempo, considerando, ainda, que as resoluções ou saídas que surgem durante a intervenção se caracterizariam como incompletas, nunca definitivas.

O que se ressalta é a potencialidade com relação à aquisição de sentido e ação, o empoderamento dos sujeitos e a capacidade de se trabalhar com as condições adversas e conflitos que naturalmente continuarão a surgir, e abandona-se qualquer pretensão que se volte à resolução de problemas ou conclusão de tarefas. Não é a proposta metodológica clínica tampouco o pesquisador que possuirão o monopólio acerca da questão dos sentidos, nem poderão responder a objetivos idealizados e, portanto, inalcançáveis: “...quaisquer sejam suas metas de compreensão global, [a clínica] se traduz, necessariamente, em démarches contingentes, limitadas e particulares" (Lévy, 2001, p. 36); esse reconhecimento e posicionamento ético acerca dos alcances e limites de sua proposta de intervenção se colocam como imprescindíveis para seu trabalho.

Vale, ainda, atentar-se às especificidades dessa noção de sentido, tão cara à proposta da clínica e, na presente exposição, inerente à discussão acerca das denominadas clínicas do trabalho: este não pretenderia atender à instância de uma verdade total sobre uma situação, a ser alcançada ou restaurada, nem a algo atribuído previamente, definido e simplesmente encoberto. É o sentido que estruturará um projeto de mudança, de um ponto de vista dinâmico, e vai se ligar à significação, como compreensão e possibilidade de elaboração, por parte dos atores envolvidos. Interessará, por fim, como uma cadeia de representações a ser construída e que parte de uma história em parte estruturada, mas ainda sendo narrada. Como nos diz Lévy (2001, p. 27), “...desse hiato, dessa contradição e dessa tensão entre o esclarecimento de um passado findo e o presente vivo e enigmático, resulta o efeito do sentido, que não é uma resposta, mas uma pergunta, que cria as condições de um devir possível".

\section{Algumas considerações finais}

As clínicas do trabalho trabalham, enfim, nessa perspectiva dialógica e dinâmica, essencial, do sujeito em relação. Consideram toda a complexidade inerente às noções de sujeito, organização e trabalho, bem como avaliam sua proposta metodológica e intervencionista de modo sempre contextual e particular, bem como restrita àquilo que pode ser apreensível e trabalhado na situação.

Ao se inserirem mais como um campo teórico e técnico aberto à construção dos saberes pontuais e contingentes, tendo como protagonistas os próprios atores sociais inseridos numa conjuntura específica, e não como uma disciplina científica estruturada que se propõe a responder, explicar e apresentar soluções previamente determinadas sobre as demandas explicitadas, possibilitam uma inserção ética e de cuidado no campo de trabalho.

São seus movimentos que visam a uma construção permanente de sentido que permitem àqueles sujeitos implicados numa determinada condição relacional, inseridos numa organização e atravessados por linhas e discursos culturais, históricos e institucionais,

\section{4}


compreenderem significados próprios de sua situação: essa atribuição de sentido, construída subjetivamente pelos atores e partilhada coletivamente, acerca dos processos vivenciados, é o que possibilita e potencializa as verdadeiras e efetivas transformações sociais.

\section{Referências}

Bendassolli, P. \& Soboll, L. A. (2011). Introdução às clínicas do trabalho: aportes teóricos, pressupostos e aplicações (pp. 3-21). In P. Bendassolli \& L. A. Soboll (Org.), Clínicas do trabalho: novas perspectivas para a compreensão do trabalho na atualidade. São Paulo: Atlas.

Bourdieu, P. (1998). Contrafogos: táticas para enfrentar a invasão neoliberal. Rio de Janeiro: Zahar.

Casadore, M. M. (2010). O sentido do trabalho na sociedade atual: suporte da identidade ou suporte para o consumo? (pp. 29-54). In F. Hashimoto (Org.), Psicologia e trabalho: desafios e perspectivas. Assis: UNESP. Assis.

Casadore, M. M. (2013). Psicossociologia e intervenção psicossociológica: alguns aspectos da pesquisa e da prática (pp. 163-182). In T. S. Emidio \& F. Hashimoto (Orgs.), Psicologia e seus campos de atuação: demandas contemporâneas. São Paulo: Cultura Acadêmica.

Chanlat, J.-F. (1995). Modos de gestão, saúde e segurança no trabalho (pp. 118-128). In E. Davel \& J. Vasconcelos (Org.), Recursos humanos e subjetividade. Petrópolis: Vozes.

Clot, Y. (2011a). Clínica do trabalho e clínica da atividade (pp. 71-83). In P. Bendassolli \& L. A. Soboll (Orgs.), Clínicas do trabalho: novas perspectivas para a compreensão do trabalho na atualidade. São Paulo: Atlas.

Clot, Y. (2011b). O início de uma história? (Prefácio, pp. xi-xiv). In P. Bendassolli \& L. A. Soboll (Orgs.), Clínicas do trabalho: novas perspectivas para a compreensão do trabalho na atualidade. São Paulo: Atlas.

Gaulejac, V. (2001). Psicossociologia e sociologia clínica (pp. 35-48). In J. N. G. Araújo \& T. C. Carreteiro (Orgs.), Cenários sociais e abordagem clínica. São Paulo: Escuta. Belo Horizonte: Fumec.

Goulart, I. B. \& Guimarães, R. F. (2002). Cenários contemporâneos do mundo do trabalho (pp. 17-30). In I. B. Goulart (Org.), Psicologia organizacional e do trabalho: teoria, pesquisa e temas correlatos. São Paulo: Casa do Psicólogo.

Enriquez, E. (1994). O papel do sujeito humano na dinâmica social (pp. 27-44). In M. Machado, E. Castro, J. N. Araújo, \& S. Roedel (Orgs.), Psicossociologia: análise social e intervenção. Petrópolis, RJ: Vozes.

Enriquez, E. (1997). A organização em análise. Petrópolis, RJ: Vozes.

Enriquez, E. (2005). Psicanálise e ciências sociais. Ágora (Rio J.). Vol.8, n.2, pp.153-174.

Enriquez, E. (2006). O homem do século XXI: sujeito autônomo ou indivíduo descartável? Revista RAE Eletrônica, 5 (1), 1-14.

Lévy, A. (2001). Ciências clínicas e organizações sociais: sentido e crise de sentido. Belo Horizonte: Autêntica/Fumec.

Lhuilier, D. (2011). Filiações teóricas das clínicas do trabalho (pp. 22-57). In P. Bendassolli \& L. A. Soboll (Orgs.), Clínicas do trabalho: novas perspectivas para a compreensão do trabalho na atualidade. São Paulo: Atlas.

Lhuilier, D. (2014). Introdução à psicossociologia do trabalho. Cadernos de Psicologia Social do Trabalho, 17 (spe 1), 5-19.

Singer, P. (2000). A crise das relações de trabalho. In A. Jerusalinsky, A. C. Merlo, \& A. L. Giongo (Orgs.), O valor simbólico do trabalho e o sujeito contemporâneo. Porto Alegre: Artes e Ofícios.

\section{Endereço para correspondência}

mmcasadore@yahoo.com.br 